\title{
A Retrospective Analysis of Clinical Manifestations, Management and Outcome of Acute Respiratory Distress Syndrome Associated with Coronavirus Disease-2019 Infection in Children
}

\author{
Mihir Sarkar ${ }^{1} \odot$, Bratesh Das ${ }^{2} \odot$, Manas K Mahapatra ${ }^{3} \odot$, Satyabrata Roychowdhoury ${ }^{4} \odot$, Sambhunath Das ${ }^{5} \odot$, Mithun C Konar ${ }^{6} \odot$
}

\begin{abstract}
Background: Acute respiratory distress syndrome (ARDS) associated with COVID-19 in children is not well described in the literature, so this study was designed to assess the severity, clinical course, different treatment measures, and outcome of this group of patients.

Patients and methods: This descriptive study was performed by retrospective chart review of children admitted in pediatric intensive care unit (PICU) in the age-group of 1 month to 12 years over the period of 6 months (July-December 2020) in a tertiary care pediatric COVID facility in eastern India. Severity of ARDS, ventilator settings, oxygenation and laboratory parameters, and outcomes were documented. Predictors associated with severe ARDS were evaluated.

Results: Among 128 laboratory-confirmed pediatric COVID-19 cases admitted in PICU, 18 (14\%) developed ARDS, 6 (33.3\%) had severe ARDS, and $3(16.6 \%)$ succumbed to death. Outcome was measured by median hospital stay [20 days (IQR 19, 21)], PICU stay [13 days (IQR 10, 16)], and 28-day ventilator-free days [14 days (IQR 13,22)]. Half $(n=9)$ of our study cohort had different comorbidities and congenital heart disease being the most common (4,22.2\%). Median positive end-expiratory pressure requirement was $10 \mathrm{~cm} \mathrm{H}_{2} \mathrm{O}(9,11)$ for invasively ventilated children ( $n=13,72.2 \%)$ along with peak inspiratory pressure of $24 \mathrm{~cm} \mathrm{H}_{2} \mathrm{O}(20,29)$ and mean airway pressure of $17 \mathrm{~cm} \mathrm{H}_{2} \mathrm{O}(14,20)$. Median oxygenation index was $13.3(10.5,18.6)$. Nine $(69.2 \%)$ out of 13 intubated children had undergone prone ventilation. C-reactive protein (CRP) and D-dimer levels were significantly high in children with severe ARDS alongside PSOFA and lung USG score.

Conclusion: Incidence of ARDS in pediatric COVID-19 though less but is not rare. Elevated CRP, D-dimer values, and high lung USG scores were associated with severe ARDS. Those who died had significant comorbidity.

Keywords: Acute respiratory distress syndrome, Children, Coronavirus disease-2019, Pediatric intensive care unit.

Indian Journal of Critical Care Medicine (2022): 10.5005/jp-journals-10071-24145
\end{abstract}

\section{INTRODUCTION}

In December 2019, a pandemic of Coronavirus disease-2019 or COVID-19 caused by SARS-CoV-2 started in the Wuhan province of China and gradually involved almost every continent. It has been seen to cause severe acute respiratory distress syndrome (ARDS), leading to intensive care unit (ICU) admission and considerable mortality. ${ }^{2}$ In an adult study, the incidence of ARDS was found to be around one-third of the admitted patients with COVID-19, and among them, more than half of the patients needed invasive ventilatory support in an ICU. ${ }^{2}$ Several studies have reported varied mortality rate from 13 to $85 \%$ among adult population. ${ }^{3,4}$ Although there are not enough data present in the pediatric age-group, early studies from China suggested less disease severity in children. ${ }^{5}$ In due course, we have learned about entities like multisystem inflammatory syndrome in children (MIS-C), which may complicate the disease process by precipitating shock and multiorgan failure. ${ }^{6}$ Later on, pediatric data have shown an increase in severity and incidence of ARDS, PICU admission rate, and requirement of ventilatory support among children affected with COVID-19.? A recent meta-analysis showed that children with comorbidities such as congenital heart disease, preexisting malignancy, CNS diseases, and chronic respiratory diseases have worse outcomes if infected with the virus. ${ }^{8}$ Alongside comorbidities and complications, adult studies showed that ARDS caused by SARS$\mathrm{CoV}-2$ is different from ARDS caused by other etiology, in respect

\footnotetext{
${ }^{1-6}$ Department of Pediatrics, Medical College, Kolkata, West Bengal, India
}

Corresponding Author: Satyabrata Roychowdhoury, Department of Pediatrics, Medical College, Kolkata, West Bengal, India, Phone: +919433765529, e-mail:drsatarc@gmail.com

How to cite this article: Sarkar M, Das B, Mahapatra MK, Roychowdhoury S, Das S, Konar MC. A Retrospective Analysis of Clinical Manifestations, Management and Outcome of Acute Respiratory Distress Syndrome Associated with Coronavirus Disease-2019 Infection in Children. Indian J Crit Care Med 2022;26(3):331-338.

Source of support: Nil

Conflict of interest: None

to time of onset from clinical insult, compliance of respiratory system, severity based on oxygenation index, and management protocols. ${ }^{9}$

Nevertheless, there is paucity of literature examining the presentation, progression, management, and prognosis of pediatric ARDS (PARDS) cases associated with COVID-19. The clinical course of adult COVID-19 associated ARDS has been described in many studies, ${ }^{2-4,9}$ but questions remain regarding optimum management of PARDS. Hence, this study was set out to understand the pattern, course, severity, and outcome of pediatric ARDS and guide therapy in the future.

o The Author(s). 2022 Open Access This article is distributed under the terms of the Creative Commons Attribution 4.0 International License (https://creativecommons. org/licenses/by-nc/4.0/), which permits unrestricted use, distribution, and non-commercial reproduction in any medium, provided you give appropriate credit to the original author(s) and the source, provide a link to the Creative Commons license, and indicate if changes were made. The Creative Commons Public Domain Dedication waiver (http://creativecommons.org/publicdomain/zero/1.0/) applies to the data made available in this article, unless otherwise stated. 


\section{Objective}

The objective of this study was to determine clinical course of children with COVID-19 ARDS. Predictors of severe ARDS were also assessed.

\section{Methodology}

This descriptive study was performed by retrospective chart review of children admitted in pediatric intensive care unit (PICU) in the age-group of 1 month to 12 years, over the period of 6 months (July 2020-December 2020) in a tertiary care-dedicated pediatric COVID facility in eastern India. Case records of all patients admitted to PICU during the study period were screened to identify the children having PARDS. Approval from institutional ethics committee was obtained and permission taken for waiving informed consent. COVID-19 infection was confirmed by real-time reverse transcription polymerase chain reaction testing a specimen of nasopharyngeal and oropharyngeal swab.

ARDS and its severity were defined using PALICC criteria in respect to oxygenation index (OI) in invasively ventilated children and $\mathrm{PaO}_{2} / \mathrm{FiO}_{2}$ (P/F) ratio in nonintubated children. ${ }^{10}$ Management of ARDS was based on lung-protective ventilation strategy according to the practice recommendation for treating children with COVID-19, endorsed by European Society of Pediatric and Neonatal Intensive Care (ESPNIC). ${ }^{11}$ All the patients who developed ARDS along with COVID-19 were initially started on pressure-regulated volume control mode (PRVC) in MAQUET Servo i ventilator, as per the running protocol in our PICU. Bedside incremental positive-end expiratory pressure (PEEP) titration was performed with continuous monitoring of $\mathrm{SpO}_{2}$, blood pressure, dynamic lung compliance and dynamic driving pressure. Optimum PEEP was determined by the level where the ceiling of $\mathrm{SpO}_{2}$ (For moderate ARDS 94\% and for severe ARDS 90\%) and dynamic compliance observed and lowest requirement of dynamic driving pressure noted. Those who responded to incremental PEEP titration were not proned. Those cases where $P / F$ ratio was $<150$ after PEEP titration were proned.

Definition from World Health Organization (WHO) was used to define pneumonia and respiratory distress with its severity. ${ }^{12}$ Acute kidney injury (AKI) was defined using the Kidney Disease: Improving Global Outcomes (KDIGO) classification, based upon a change in serum creatinine level and creatinine clearance. ${ }^{13}$ Pediatric Surviving Sepsis Guidelines were used to define sepsis and septic shock, and MIS-C was defined according to WHO definition. ${ }^{14,15}$

Demographic, clinical, and radiographic data and different relevant laboratory parameters were extracted from medical records during the PICU stay. Investigations performed within 24 hours of PICU admission were taken for analysis. The cut-off values for different laboratory markers were taken asthrombocytopenia $\left(<150 \times 10^{3} / \mathrm{mm}^{3}\right)$, high procalcitonin $(>2 \mathrm{ng} / \mathrm{mL})$, raised N-Terminal pro-BNP (>125 pg/mL), elevated IL-6 $(>7 \mathrm{pg} / \mathrm{mL})$, hyperferritinemia $(>700 \mathrm{ng} / \mathrm{mL}),{ }^{16}$ raised $C$-reactive protein (>10 mg/L), and high D-dimer $(>0.5 \mu \mathrm{g} / \mathrm{mL})$. Basic laboratory investigations were taken into our records, and cut-off values were defined as per age-specific standards. ${ }^{17}$ To monitor organ function, pediatric sequential organ failure assessment (pSOFA) score was taken at PICU admission. ${ }^{18}$ The type of respiratory support and its duration during the course of illness was recorded. Arterial blood gas (ABG) measurements, ventilator modes and settings, oxygenation-related variables, maximum ventilator settings, and their duration were extracted from our records.
Bedside lung USG was done by Philips HD7 (Philips Healthcare, Netherlands) with the high-frequency linear probe ( $\mathrm{L} 7-12 \mathrm{mHz}$ ) at the time of PICU admission, and lung USG score was calculated in 12 zones for each patient. ${ }^{19,20}$ Available echocardiography findings of the patients were noted. According to our PICU protocol, ejection fraction $<55 \%$ by modified Simpson's method was considered as systolic dysfunction. Records of coronary abnormalities, valvular insufficiencies and pericardial effusion were extracted. According to the COVID-19 management guideline, CT scan is not recommended for diagnosis and routine management in pediatric patients. In the study group in one patient CT scan was performed as the patient was requiring prolonged high-flow nasal cannula (HFNC) support in postextubation period.

In case of mild ARDS, we gave trial of HFNC, and in moderate ADRS, we tried noninvasive ventilation (NIV) initially, if there are no significant neurological or hemodynamic issues. But, if patient did not improve after getting high-flow oxygen at $2 \mathrm{~L} / \mathrm{kg} /$ minute and $60 \% \mathrm{FiO}_{2}$ for 2 hours, we considered it as HFNC failure and trial of NIV was given. In case of noninvasive ventilation, if the requirement of PEEP was $>8 \mathrm{~cm} \mathrm{H}_{2} \mathrm{O}$ and PIP of $>15 \mathrm{~cm} \mathrm{H}_{2} \mathrm{O}$ and $\mathrm{FiO}_{2}>60 \%$, we termed it as NIV failure and patient shifted to invasive ventilation. Severe ARDS, inability to maintain airway, hemodynamic instability requiring high dose of inotropes were the indications of invasive ventilation, straight way.

We compared the relevant laboratory investigations, inflammatory markers, lung USG scores, organ dysfunction scores between patients who had severe ARDS with those having mild to moderate ARDS. Outcomes were measured in the form of PICU stay, 28-day ventilator-free days, hospital stay, and mortality.

Data were entered and analyzed using the statistical package SPSS (Statistical Package for the Social Science; SPSS Inc., Chicago, Illinois, USA) version 23. Continuous variables were expressed as median, interquartile range, and mean standard deviation; while categorical variables, as numbers and percentages. Comparison of laboratory parameters, organ dysfunction, lung USG scores between the two groups-who had severe ARDS and who had mild to moderate ARDS category, were analyzed by Fischer's exact test or Chi-square test for categorical variables, and Mann-Whitney tests or unpaired $t$-test for continuous variable. $p$ value less than 0.05 was considered significant.

\section{Results}

During the defined period, 128 patients were admitted in PICU, and 18 (14\%) had PARDS and required respiratory support in the form of invasive or noninvasive ventilation. The median age of the cohort was 7.5 (IQR 3, 25.2) months, with a preponderance of female sex $(10,55.5 \%)$ (Table 1). Eleven (61.1\%) patients were infants, nine (50\%) patients had comorbidities and predominant being complex congenital heart disease (4, 22.2\%). Respiratory distress was the most common symptom $(14,77.7 \%)$, and the median duration of symptoms was 4 days (IQR 3,5) before admission. Eleven (61.1\%) patients developed shock, and among them, nine were invasively ventilated, nine had myocardial dysfunction, and four patients were blood culture positive. The median PICU stay of the patients having shock were 15 days (IQR 13, 17.5), whereas those who did not develop shock had a median PICU stay of 12 days (IQR 9.5, 13.5). The median value of pSOFA score was 11 (IQR 7.25, 12), which points out the significant disease burden in our study cohort. Corticosteroids $(16,88.8 \%)$ and 
Table 1: Demographics and clinical characteristics of children with ARDS and COVID-19 infection $(n=18)$

\begin{tabular}{|c|c|c|c|c|}
\hline Parameters & \multicolumn{4}{|c|}{ Median or percentage or mean values } \\
\hline Age (in months) & \multicolumn{4}{|c|}{$7.5($ IQR 3, 25.2) } \\
\hline Sex (female) & \multicolumn{4}{|c|}{10 (55.5\%) } \\
\hline Fever & \multicolumn{4}{|c|}{$12(66.6 \%)$} \\
\hline Cough & \multicolumn{4}{|c|}{$10(55.5 \%)$} \\
\hline Respiratory distress & \multicolumn{4}{|c|}{$14(77.7 \%)$} \\
\hline Shock & \multicolumn{4}{|c|}{$11(61.1 \%)$} \\
\hline Myocardial dysfunction & \multicolumn{4}{|c|}{$9(50 \%)$} \\
\hline MIS-C & \multicolumn{4}{|c|}{$2(11.1 \%)$} \\
\hline AKI & \multicolumn{4}{|c|}{$4(22.2 \%)$} \\
\hline Convulsion & \multicolumn{4}{|c|}{$9(50 \%)$} \\
\hline Comorbidity & \multicolumn{4}{|c|}{$9(50 \%)$} \\
\hline Neurological abnormality & \multicolumn{4}{|c|}{$3(16.6 \%)$} \\
\hline Congenital heart disease & \multicolumn{4}{|c|}{$4(22.2 \%)$} \\
\hline Childhood malignancy & \multicolumn{4}{|c|}{$2(11.1 \%)$} \\
\hline Median duration of symptoms & \multicolumn{4}{|c|}{4 days (IQR 3,5$)$} \\
\hline \multicolumn{5}{|l|}{ Vital signs at the time of admission } \\
\hline Temperature $\left({ }^{\circ} \mathrm{F}\right)$ & \multicolumn{4}{|c|}{100.6 (IQR 98.6, 101.1) } \\
\hline Heart rate & \multicolumn{4}{|c|}{154 (IQR 123.5, 163.5) } \\
\hline $\mathrm{SpO}_{2}(\%)$ & \multicolumn{4}{|c|}{$95.5($ IQR $93.2,97)$} \\
\hline Respiratory rate & \multicolumn{4}{|c|}{56 (IQR 41, 60.2) } \\
\hline Median pSOFA score & \multicolumn{4}{|c|}{$11($ IQR $7.25,12)$} \\
\hline \multicolumn{5}{|l|}{$\begin{array}{l}\text { Treatment received } \\
\text { Vasopressors or inotropes used }\end{array}$} \\
\hline Noradrenaline & \multicolumn{4}{|c|}{$12(85.7 \%)$} \\
\hline Adrenaline & \multicolumn{4}{|c|}{$7(50 \%)$} \\
\hline Dobutamine & & 12 & $.7 \%)$ & \\
\hline Vasopressin & & & $.5 \%)$ & \\
\hline Levosemendan & & & 1\%) & \\
\hline Milrinone & & & 1\%) & \\
\hline Median VIS & & $65(\mathrm{IQ}$ & $2.5,78.7)$ & \\
\hline Median duration (in days) & & & $5,9)$ & \\
\hline & Mild ARDS & Moderate ARDS & Severe ARDS & Total \\
\hline Patients needed vasopressor support & 2 & 6 & 6 & $14(77.7 \%)$ \\
\hline Intravenous immunoglobulin & 1 & 2 & 3 & $6(33.3 \%)$ \\
\hline Remdesivir & 1 & 8 & 6 & $15(83.3 \%)$ \\
\hline LMWH & 0 & 4 & 4 & $8(44.4 \%)$ \\
\hline Neuromuscular blockade & 0 & 0 & 5 & $5(27.7 \%)$ \\
\hline Steroid & 1 & 9 & 6 & $16(88.8 \%)$ \\
\hline Type of steroid & $\begin{array}{r}\text { Methyl } \\
14\end{array}$ & $\begin{array}{l}\text { rednisolone } \\
(87.5 \%)\end{array}$ & $\begin{array}{r}\text { Dexam } \\
2(1\end{array}$ & $\begin{array}{l}\text { nasone } \\
\text { s\%) }\end{array}$ \\
\hline Mean duration of steroid therapy & & & & \\
\hline Renal replacement therapy & & & 5\%) & \\
\hline Need for anticonvulsants & & & $\%)$ & \\
\hline Need for RICP management & & & $7 \%)$ & \\
\hline
\end{tabular}

MIS-C, Multisystem inflammatory syndrome in children; AKI, acute kidney injury; pSOFA, pediatric sequential organ failure assessment; VIS, vasoactive-inotropic score; LMWH, low-molecular-weight heparin; RICP, raised intracranial pressure

intravenous immunoglobulin $(6,33.3 \%)$ were used as decided by the treating physician. Out of 16 patients who received steroid, two required $10 \mathrm{mg} / \mathrm{kg} /$ day pulse dose of methylprednisolone due to the presence of MIS-C. Rest of the 14 patients were treated with standard dose of either methylprednisolone (N:12) or dexamethasone $\mathrm{e}^{21}(\mathrm{~N}: 2)$ as per the discretion of treating physician. Intravenous steroid therapy was stopped as and when there was resolution of fever and decreasing trend of inflammatory markers and the mean duration being 5 days. Intravenous immunoglobulin was given to six patients at a dose of $2 \mathrm{~g} / \mathrm{kg}$ over 48 hours; among 
them three had severe ( $\mathrm{EF}<40 \%$ ) and other three had moderate myocardial dysfunction (EF: 40-55\%). Two patients met diagnostic criteria of MIS-C. Remdesivir was administered in 15 (83.3\%) patients, and 8 (44.4\%) patients received low-molecular-weight heparin (LMWH).

Among all the patients $(n=18)$ in our cohort, six had severe, nine had moderate, and three had mild ARDS. Flowchart 1 describes the different types of respiratory support received by the patient according to the severity of ARDS and disease progression time line. Median PEEP requirement was $10 \mathrm{~cm} \mathrm{H}_{2} \mathrm{O}($ IQR 9, 11) for invasively ventilated children, set tidal volume was $7 \mathrm{~mL} / \mathrm{kg}$ (IQR 6, 7.5) along with peak inspiratory pressure of $24 \mathrm{~cm} \mathrm{H} \mathrm{H}_{2} \mathrm{O}$ (IQR 20, 29) and median airway pressure (MAP) of $17 \mathrm{~cm} \mathrm{H}_{2} \mathrm{O}$ (IQR 14, 20) (Table 2). Nine (69.2\%) patients among all the intubated children had undergone prone ventilation. The mean duration of proning was 32 hours (IQR 0,49.5), and median ventilator stay was 8 days (IQR 7, 9). None of the patients who needed noninvasive ventilation were kept prone, because they didn't tolerate awake proning (Suppl. Table 1).

Median $\mathrm{Hb} \%$ of all the patients with ARDS with COVID-19 was $7.9 \mathrm{~g} / \mathrm{dL}$ (IQR 6.5, 8.7), and thrombocytopenia was noted in seven (38.8\%) children (Table 3). Seventeen (94.4\%) patients had elevated levels of C-reactive protein (CRP), and same number of patients had raised D-dimer. On lung USG, breakage of pleural line $(15,83.3 \%)$ followed by posterior subpleural consolidation (14,77.7\%) over more than two zones were the two most common findings in our study cohort.

On comparison of laboratory parameters, CRP ( $p$-value: 0.001$)$ and D-dimer ( $p$-value: 0.004 ) were significantly elevated in patients with severe ARDS. Notably, higher pSOFA ( $p$-value: 0.001 ) and lung USG score ( $p$-value: 0.001 ) within first 24 hours of PICU admission were observed in severe ARDS (Table 4).

In this study, the median stay in PICU was 13 days (IQR 10, 16), and median hospital stay was 14 days (IQR 13, 22). Three
(16.6\%) patients died in PICU, and among them one had tetralogy of fallot with absent pulmonary valve, one other patient had neurodegenerative disorder with super-refractory convulsion leading to brain death, and the third patient had acute myeloid leukemia with massive intracranial bleed. Details of their ARDS severity and ventilator strategies were described in Table 2.

\section{Discussion}

In the present study, $14 \%(n=18)$ of PICU-admitted COVID-19 pediatric patients suffered from ARDS. Most of them $(13,72.2 \%)$ required invasive mechanical ventilation. Comorbidity was present in half of the patients and was also contributing factor for mortality. Median OI was 13.3 (IQR 10.5, 18.6), median PEEP of $10 \mathrm{~cm} \mathrm{H}_{2} \mathrm{O}$, PIP of $24 \mathrm{~cm} \mathrm{H}_{2} \mathrm{O}$ were required in our cohort. Along with $\mathrm{P} / \mathrm{F}$ ratio, CRP and D-dimer were found to be associated with severity of the disease.

In an early report from China, it has been described that proportion of "severe and critical" cases was 10.6\% in infant age-group, and severe illness was defined as ARDS with or without shock, encephalopathy, myocardial injury or heart failure, coagulation dysfunction, and AKI. But details of clinical analysis of these children were not included in this study. ${ }^{5} \mathrm{~A}$ multicenter study from Italy reported that out of 168 infected children, 14 patients developed severe acute respiratory illness. ${ }^{22}$ Another report from Europe mentioned that 10 out of 198 pediatric patients had ARDS, and all of them required mechanical ventilation. ${ }^{23}$

In our study, the median age of participants was 7.5 months, and $55.5 \%$ of the study population were female. In the early part of pandemic, infants were seen to be more vulnerable, ${ }^{5}$ but a more recent study from New York, which was designed to describe clinical manifestation and outcome of critically ill children, had 30\% ARDS cases. In this study, male developed more ARDS, and median age was also high (15 years, IQR 9, 19). ${ }^{24}$

Flowchart 1: Different respiratory supports used in patients with ARDS

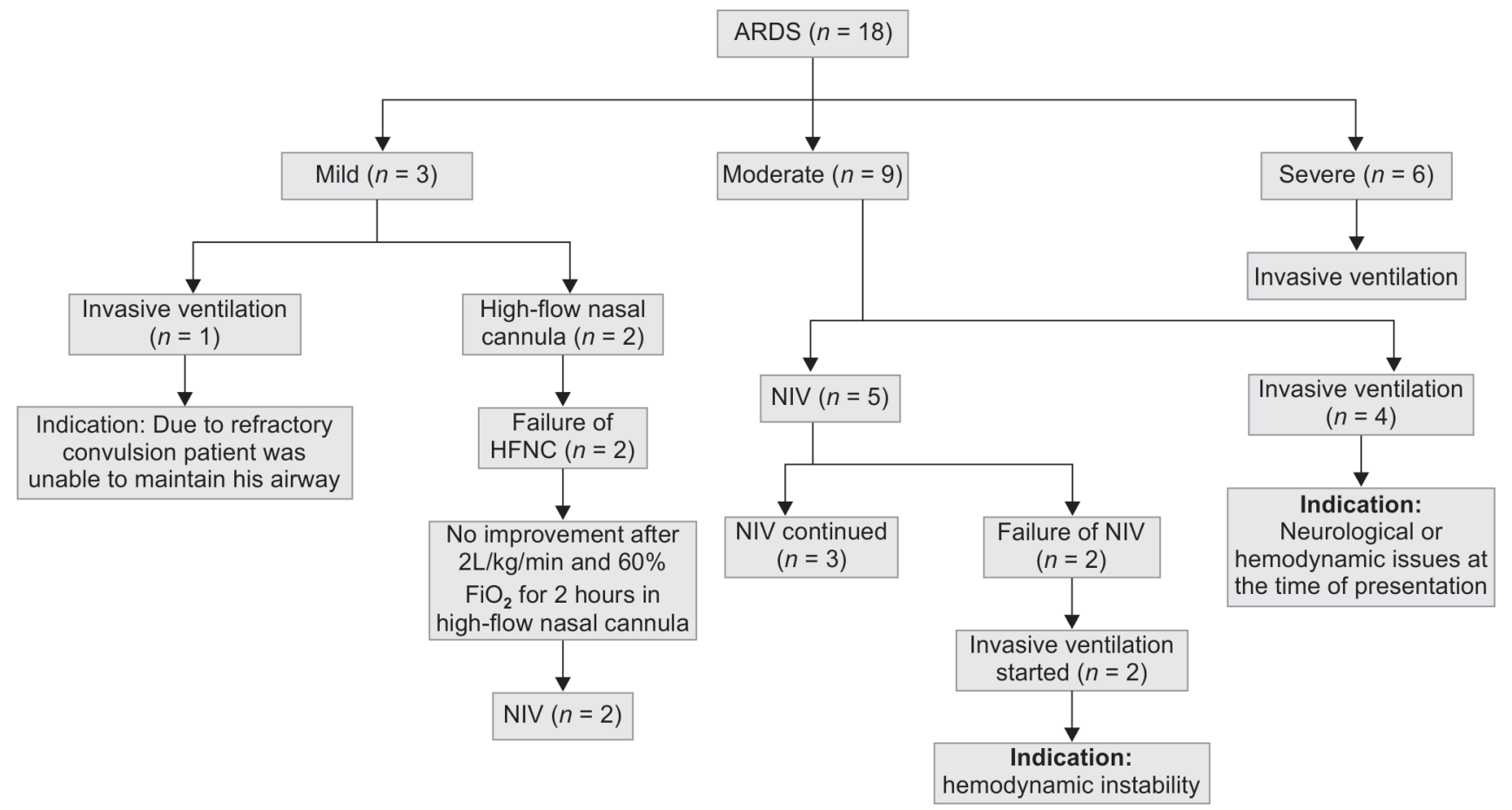




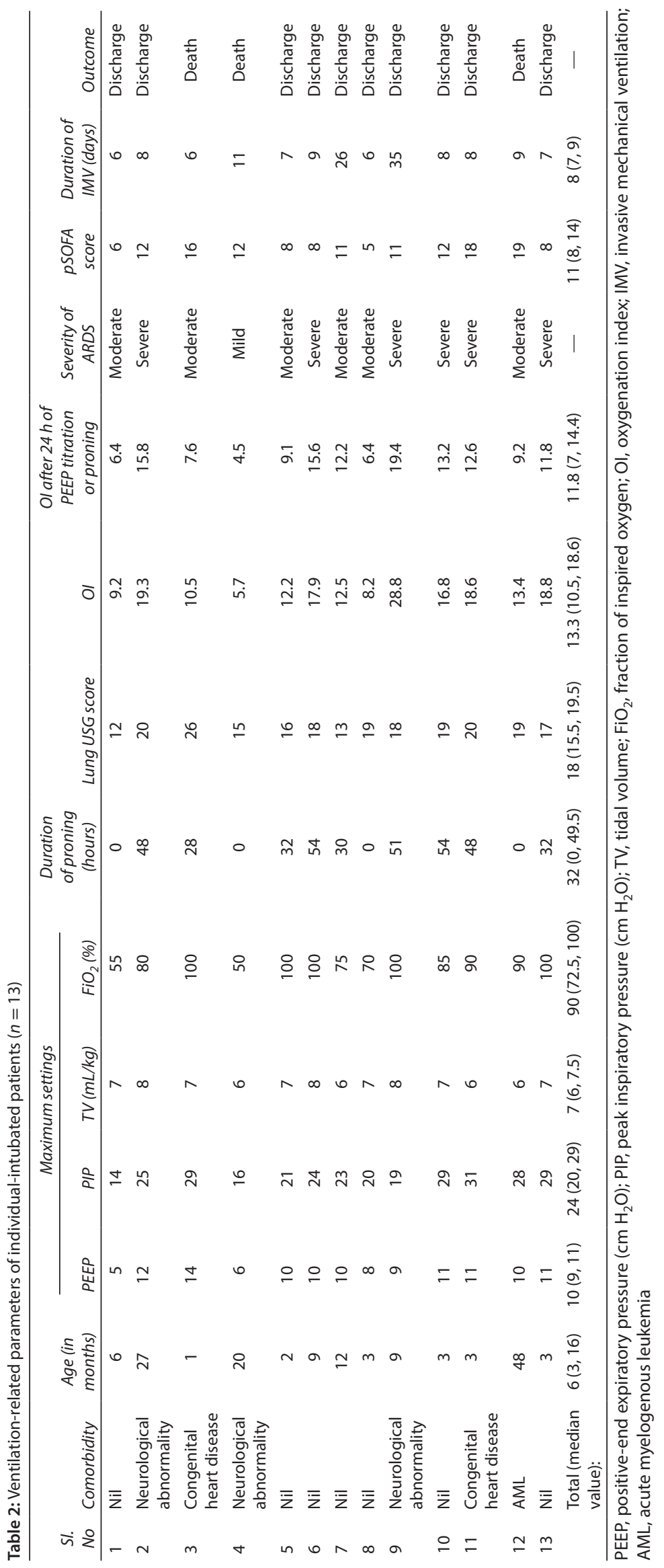


Table 3: Laboratory parameters in children with ARDS and COVID-19 infection $(n=18)$

\begin{tabular}{|c|c|}
\hline Laboratory parameters & Median values or percentage in PICU admitted patients \\
\hline $\mathrm{Hb} \%(\mathrm{~g} / \mathrm{dL})$ & $7.9(6.5,8.7)$ \\
\hline Platelets $\left(\leq 150 \times 10^{3} / \mathrm{mm}^{3}\right)$ & $7(38.8 \%)$ \\
\hline TLC (cells $\left./ \mathrm{mm}^{3}\right)$ & $10240(8700,18525)$ \\
\hline ALC (cells $/ \mathrm{mm}^{3}$ ) & $2687(1768.5,5316)$ \\
\hline $\mathrm{TSB}(\mathrm{mg} / \mathrm{dL})$ & $0.6(0.4,0.9)$ \\
\hline ALT (IU/L) & $42(27,74.2)$ \\
\hline AST (IU/L) & $65(38.7,172.5)$ \\
\hline $\begin{array}{l}\text { Creatinine (higher than age-specific } \\
\text { cut-off) }\end{array}$ & $13(72.2 \%)$ \\
\hline Ferritin (>700 ng/mL) & $5(27.7 \%)$ \\
\hline NT Pro-BNP (>125 pg/mL) & $13(72.2 \%)$ \\
\hline IL-6 (>7 pg/mL) & $15(83.3 \%)$ \\
\hline C-reactive protein (>10 mg/L) & $17(94.4 \%)$ \\
\hline D-dimer $(>0.5 \mu \mathrm{g} / \mathrm{mL})$ & $17(94.4 \%)$ \\
\hline Procalcitonin level (>2 ng/mL) & $7(38.8 \%)$ \\
\hline $\begin{array}{l}\text { Bedside echocardiography } \\
\text { EF }<40 \% \\
\text { EF } 40-55 \% \\
\text { EF }>55 \% \\
\text { Pericardial effusion }\end{array}$ & $\begin{array}{l}3(16.6 \%) \\
6(33.3 \%) \\
9(50 \%) \\
1(5.5 \%)\end{array}$ \\
\hline $\begin{array}{l}\text { Lung USG } \\
\text { Posterior subpleural consolidation } \\
\text { Breakage of pleural line } \\
\text { Collapse of one or more lobes } \\
\text { Pleural effusion }\end{array}$ & $\begin{array}{c}14(77.7 \%) \\
15(83.3 \%) \\
3(16.6 \%) \\
1(5.5 \%)\end{array}$ \\
\hline Infiltrates in chest X-ray & $16(88.8 \%)$ \\
\hline $\begin{array}{l}\text { Positive cultures during PICU stay } \\
\text { +Blood culture } \\
\text { +Bronchoalveolar lavage culture } \\
\text { +CSF culture }\end{array}$ & $\begin{array}{l}4(22.2 \%) \\
1(5.5 \%) \\
1(5.5 \%)\end{array}$ \\
\hline Outcome parameters & \\
\hline Median PICU stay & 13 days (IQR 10, 16) \\
\hline Median 28-day ventilator-free days & 20 days (IQR 2,21$)$ \\
\hline Median hospital stay & 14 days (IQR 13, 22) \\
\hline Death & $3(16.6 \%)$ \\
\hline
\end{tabular}

TLC, total leukocyte count; ALC, absolute lymphocyte count; TSB, total serum bilirubin; ALT, alanine aminotransferase; AST, aspartate aminotransferase

Table 4: Comparison of laboratory parameters, severity, and oxygenation indices between patients suffering from mild to moderate and severe ARDS

\begin{tabular}{lccc}
\hline Parameters & Severe ARDS $(n=6)$ & Mild to moderate ARDS $(n=12)$ & $p$ value \\
\hline $\mathrm{Hb}(\mathrm{g} / \mathrm{dL})$ & $8.1(6.9,8.3)$ & $6.9(6.2,11.4)$ & 0.960 \\
$\mathrm{TLC}\left(\mathrm{cells} / \mathrm{mm}^{3}\right)$ & $8750(7600,11300)$ & $14100(10700,40000)$ & 0.056 \\
$\mathrm{ALC}\left(\mathrm{cells} / \mathrm{mm}^{3}\right)$ & $2436(1824,5000)$ & $5564(1410,13175)$ & 0.490 \\
$\mathrm{CRP}(\mathrm{mg} / \mathrm{L})$ & $96.7(58.4,117)$ & $18.4(14,22.5)$ & 0.001 \\
Pro-BNP $(\mathrm{pg} / \mathrm{mL})$ & $1153(413.4,12466)$ & $855(103.1,1076)$ & 0.138 \\
$\mathrm{IL}-6(\mathrm{pg} / \mathrm{mL})$ & $72.9(57.4,77.6)$ & $28.4(25.6,37)$ & 0.238 \\
Ferritin $(\mathrm{ng} / \mathrm{mL})$ & $596.4(187,737.3)$ & $110.2(97.4,111.4)$ & 0.138
\end{tabular}




\begin{tabular}{lccc} 
D-dimer $(\mu \mathrm{g} / \mathrm{mL})$ & $5.02(4.2,7.8)$ & $1.2(0.7,1.3)$ & 0.004 \\
pSOFA score & $12(11,13)$ & $5(4,6)$ & 0.001 \\
$\mathrm{P} / \mathrm{F}$ ratio & $112.7(102.5,132.2)$ & $198.1(187.6,212.8)$ & 0.001 \\
$\mathrm{PaO}_{2}$ & $112.7(106.3,139.9)$ & $158.5(149,178)$ & 0.048 \\
$\mathrm{PaCO}_{2}$ & $59(51.7,62)$ & $46(42,51)$ & 0.020 \\
USG score & $18(16,19)$ & $9(8,9)$ & $\mathbf{0 . 0 0 1}$ \\
\hline Bold values indicate significant $p$ value $(p<0.05)$ &
\end{tabular}

Among the comorbidities we recorded in our cohort, congenital heart disease was most common followed by neurological abnormalities and childhood malignancy. Researchers from other parts of the world had also confirmed high rate of comorbidities among the critically ill children admitted in PICU due to COVID-19 infection. $8,25,26$

It was seen in our study that CRP and D-dimer were the most frequently elevated inflammatory markers (in $94.4 \%$ patients for both) followed by IL-6 (83.3\%) and procalcitonin (38.8\%). NT-pro BNP was elevated in 13 (72.2\%) patients, whereas myocardial dysfunction was seen in 9 (50\%) patients. Hence, NT-Pro BNP may increase probably in states of heightened inflammation besides being a marker for heart failure. Thrombocytopenia was evident in $38.8 \%$ cases in our cohort. High levels of IL- 6 and low platelet count were noted to be associated with pediatric ARDS by Derespina et al. ${ }^{24} \mathrm{~A}$ study from UK found that thrombocytopenia, high neutrophil count, and elevated CRP were associated with PICU admission. ${ }^{27}$

Study by Musolino et al.in a tertiary care hospital of Rome ${ }^{28}$ found vertical artifact (70\%), pleural irregularities (60\%), areas of white lung (10\%), and subpleural consolidation (10\%) in lung USG in 10 consecutively admitted children with COVID-19. In our study, most common lung USG findings were breakage of pleural line (83.3\%) followed by posterior subpleural consolidation (77.7\%). Severe ARDS cases were significantly associated with high lung USG score.

The study from New York reported that 18 out of 21 COVID-19-infected children with ARDS were supported by invasive mechanical ventilation (IMV) and 3 required proning. Their median IMV duration was 191.4 hours $(107.5,309.5) .{ }^{24}$ Barbosa et al. from Brazil reported that 14 out of 79 children (18\%) required invasive mechanical ventilation (IMV) with median PEEP requirement of $9.5 \mathrm{~cm} \mathrm{H}_{2} \mathrm{O}$ and median duration of IMV of 7.5 days (IQR 5, 10). ${ }^{25}$ In this study, six children were classified to have severe ARDS and three patients required intermittent proning. In our study, 13 out of 18 patients required invasive mechanical ventilation. Lung protective ventilation strategies were followed and 9 out of $13(69.2 \%)$ patients required proning for mean duration of 15.6 hours/day. The median duration of IMV in our study was 8 days (IQR 7, 9). Application of prone ventilation was higher in our study in comparison with other studies. ${ }^{24,25}$ On contrary, Chao et al. ${ }^{7}$ had shown that lung protective strategies were not sufficient to manage ARDS children with mechanical ventilation in their study cohort as they required median PEEP of $10 \mathrm{~cm} \mathrm{H}_{2} \mathrm{O}$ and median PIP of $35 \mathrm{~cm} \mathrm{H}_{2} \mathrm{O}$ on day 3 of ventilation.

The main limitation of our study was that it was a single-center retrospective study. Due to small sample size, multivariate analysis to determine independent predictors of severe ARDS was not possible. A multicenter study could have provided a more representative data on pediatric ARDS associated with COVID-19 in a developing country like India.

But till date, this study is one of the largest studies analyzing different aspects of presentation, treatment, and outcome of pediatric ARDS due to COVID-19. Data on pediatric COVID-19
ARDS are rare and insufficient. So this study may help bridge this deficiency and contribute to formulate effective management strategies for pediatric ARDS.

\section{Conclusion}

COVID-19 can cause ARDS in children with varying severity. Elevated CRP, D-dimer values, and high lung USG scores at PICU admission can be useful marker to predict severe ARDS. All diseased patients had significant comorbidity.

\section{OrCID}

Mihir Sarkar (ㄴ) https://orcid.org/0000-0002-7393-9022

Bratesh Das (1) https://orcid.org/0000-0002-3225-8837

Manas KMahapatra 으. https://orcid.org/0000-0002-1310-0006

Satyabrata Roychowdhoury 1 https://orcid.org/0000-0003-3128-6104

Sambhunath Das (10 https://orcid.org/0000-0002-0269-235X

Mithun CKonar (1) https://orcid.org/0000-0001-8066-4170

\section{Supplementary Material}

The supplementary Table 1 is available online on the website of www.IJCCM.org

\section{References}

1. Huang C, Wang Y, Li X, Ren L, Zhao J, Hu Y, et al. Clinical features of patients with 2019 novel coronavirus in Wuhan, China. Lancet 2020;395(10223):497-506. DOI: 10.1016/S0140-6736(20)30183-5.

2. Tzotzos SJ, Fischer B, Fischer H, Zeitlinger M. Incidence of ARDS and outcomes in hospitalized patients with COVID-19: a global literature survey. Crit Care 2020;24(1):516. DOI: 10.1186/s13054-020-03240-7.

3. Dreher M, Kersten A, Bickenbach J, Balfanz P, Hartmann B, Cornelissen $C$, et al. The characteristics of 50 hospitalized COVID19 patients with and without ARDS. Dtsch Arztebl Int 2020;117(16): 271-278. DOI: 10.3238/arztebl.2020.0271.

4. Zhou F, Yu T, Du R, Fan G, Liu Y, Liu Z, et al. Clinical course and risk factors for mortality of adult inpatients with COVID-19 in Wuhan, China: a retrospective cohort study. Lancet 2020;395(10229): 1054-1062. DOI: 10.1016/ S0140-6736(20)30566-3.

5. Dong Y, Mo X, Hu Y, Qi X, Jiang F, Jiang Z. Epidemiology of COVID-19 among children in China. Pediatrics 2020;145(6):e20200702. DOI: 10.1542/peds.2020-0702.

6. Jiang L, Tang K, Levin M, Irfan O, Morris SK, Wilson K, et al. COVID-19 and multisystem inflammatory syndrome in children and adolescents. Lancet Infect Dis 2020;20(11):e276-e288. DOI: 10.1016/ S1473-3099(20)30651-4.

7. Chao JY, Derespina KR, Herold BC, Goldman DL, Aldrich M, Weingarten J, et al. Clinical characteristics and outcomes of hospitalized and critically ill children and adolescents with coronavirus disease 2019 at a tertiary care medical center in New York City. J Pediatr 2020;223:14-19.e2. DOI: 10.1016/j.jpeds.2020.05.006.

8. Tsankov BK, Allaire JM, Irvine MA, Lopez AA, Sauvé LJ, Vallance BA, et al. Severe COVID-19 infection and pediatric comorbidities: a systematic review and meta-analysis. Int J Infect Dis 2021;103: 246-256. DOI: 10.1016/j.ijid.2020.11.163. 
9. Li X, Ma X. Acute respiratory failure in COVID-19: is it "typical" ARDS? Crit Care 2020;24(1):198. DOI: 10.1186/s13054-020-02911-9.

10. The Pediatric Acute Lung Injury Consensus Conference Group. Pediatric acute respiratory distress syndrome: consensus recommendations from the pediatric acute lung injury consensus conference. Pediatr Crit Care Med 2015;16:428-439. DOI: 10.1097/PCC.0000000000000350.

11. Kneyber MCJ, de Luca D, Calderini E, Jarreau PH, Javouhey $E$, Lopez-Herce J, et al. Section Respiratory Failure of the European Society for Paediatric and Neonatal Intensive Care. Recommendations for mechanical ventilation of critically ill children from the Paediatric Mechanical Ventilation Consensus Conference (PEMVECC). Intensive Care Med 2017;43(12):1764-1780. DOI: 10.1007/s00134-017-4920-z. Epub 2017 Sep 22.

12. World Health Organization. Pocket book for hospital care of children: guidelines for the management of common illness with limited resources, Geneva. 2013. Available from: https://www.who.int/ maternal_child_adolescent/documents/child_hospital_care/en/.

13. Kellum JA, Lameire N; KDIGO AKI Guideline Work Group. Diagnosis, evaluation, and management of acute kidney injury: a KDIGO summary (Part 1). Crit Care 2013;17(1):204. DOI: 10.1186/cc11454.

14. Weiss SL, Peters MJ, Alhazzani W, Agus MSD, Flori HR, Inwald DP, et al. Surviving sepsis campaign international guidelines for the management of septic shock and sepsis-associated organ dysfunction in children. Pediatr Crit Care Med 2020;21(2):e52-e106. DOI: 10.1097/PCC.0000000000002198.

15. World Health Organization. Multisystem inflammatory syndrome in children and adolescents temporally related to COVID-19. Scientific brief. 2020. Available from: https://www.who.int/news-room/ commentaries/detail/multisystem-inflammatory-syndrome-inchildren-and-adolescents-with-covid-19.

16. Webb BJ, Peltan ID, Jensen P, Hoda D, Hunter B, Silver A, et al. Clinical criteria for COVID-19-associated hyperinflammatory syndrome: a cohort study. Lancet Rheumatol 2020;2(12):E764-E773. DOI: 10.1016/ S2665-9913(20)30343-X.

17. Kliegman RM, Geme JS. Nelson textbook of pediatrics. 21st ed. Philadelphia, PA: Elsevier; 2020.

18. Matics TJ, Bubeck-Wardenburg J, Sanchez-Pinto N. 1332: the PSOFA score: a modified sequential organ failure assessment score for pediatric patients. Crit Care Med 2016;44(12):408. DOI: 10.1097/01. ccm.0000510006.49298.fb.

19. Volpicelli G, Elbarbary M, Blaivas M, Lichtenstein DA, Mathis G, Kirkpatrick $A W$, et al. International evidence-based recommendations for point-of-care lung ultrasound. Intensive Care Med 2012;38: 577-591. DOI: 10.1007/s00134-012-2513-4.

20. Ji L, Cao C, Gao Y, Zhang W, Xie Y, Duan Y, et al. Prognostic value of bedside lung ultrasound score in patients with COVID-19. Crit Care 2020;24(1):700. DOI: 10.1186/s13054-020-03416-1.

21. RECOVERY Collaborative Group, Horby P, Lim WS, Emberson JR, Mafham M, Bell JL, et al. Dexamethasone in hospitalized patients with Covid-19. N Engl J Med 2021;384(8):693-704. DOI: 10.1056/ NEJMoa2021436.

22. Garazzino S, Montagnani $C$, Donà D, Meini A, Felici E, Vergine G, et al. Multicentre Italian study of SARS-CoV-2 infection in children and adolescents, preliminary data as at 10 April 2020. Euro Surveill 2020;25(18):2000600. DOI: 10.2807/15607917.ES.2020.25.18.2000600.

23. Gotzinger F, Santiago-Garcia B, Noguera-Julian A, Lanaspa M, Lancella L, Calò Carducci Fl, et al. COVID-19 in children and adolescents in Europe: a multinational, multicentre cohort study. Lancet Child Adolesc Health 2020;4(9):653-661. DOI: 10.1016/S23524642(20)30177-2.

24. Derespina KR, Kaushik S, Plichta A, Conway EE Jr, Bercow A, Choi J, et al. Clinical manifestations and outcomes of critically ill children and adolescents with coronavirus disease 2019 in New York City [published online ahead of print, 2020 Jul 16]. J Pediatr 2020;226: 55-63.e2. DOI: 10.1016/j.jpeds.2020.07.039.

25. Prata Barbosa A, Lima Setta F, Dos Santos FR, Lanziotti VS, de Castro REV, de Souza DC, et al. Pediatric patients with COVID-19 admitted to intensive care units in Brazil: a prospective multicenter study. J Pediatr (RioJ) 2020;96(5):582-592. DOI: 10.1016/j.jped.2020.07.002.

26. Shekerdemian LS, Mahmood NR, Wolfe KK, Riggs BJ, Ross CE, McKiernan CA, et al. Characteristics and outcomes of children with Coronavirus Disease 2019 (COVID-19) infection admitted to US and Canadian pediatric intensive care units. JAMA Pediatr 2020;174(9):868-873. DOI: 10.1001/jamapediatrics.2020.1948.

27. Swann OV,Holden KA, Turtle L, Fairfield CJ, Seth S, Halpin S, et al.Clinical characteristics of children and young people admitted to hospital with covid-19 in United Kingdom: prospective multicentre observational cohort study. British Medical Journal 2020;370:m3249. DOI: 10.1136/ bmj.m3249.

28. Musolino AM,Supino MC, Buonsenso D, FerroV,Valentini P, Magistrelli A, et al. Lung ultrasound in children with COVID-19: preliminary findings. Ultrasound Med Biol 2020;46(8):2094-2098. DOI: 10.1016/ j.ultrasmedbio.2020.04.026. 